\title{
Mycetomas: an epidemiological, etiological, clinical, laboratory and therapeutic review*
}

\author{
Carmelia Matos Santiago Reis ${ }^{1}$
}

\author{
Eugenio Galdino de Mendonça Reis-Filho ${ }^{2}$
}

DOI: http:/ / dx.doi.org/10.1590/abd1806-4841.20187075

\begin{abstract}
Mycetoma is a chronic suppurative disease of the skin and subcutaneous tissue, characterized by a symptomatic triad: tumor, fistulas and grains. It can be caused by fungi (eumycetoma) and bacteria (actinomycetoma), with similar clinical features. Diagnosis is based on the clinical presentation and identification of the etiological agents in the tissue, by mycological/bacteriological, histopathological and immunohistochemical tests. It is important to specify the fungal or bacterial etiology, because the treatments are different. An approach that involves early diagnosis, the use of systemic antibiotics or antifungal agents, including surgical removal of lesions, is the basis for the treatment of these diseases. In this review, the most commonly used diagnostic methods and treatments will be discussed. Also, we will review the history of the disease through epidemiological and etiological aspects.
\end{abstract}

Keywords: Antifungal agents; Fungi; Mycetoma; Mycology

\section{INTRODUCTION}

Mycetoma is a chronic suppurative infection of the skin and subcutaneous tissues that affects the lower limbs in more than $80 \%$ of cases. ${ }^{1}$ The disease is characterized by a symptomatic triad: swelling of the affected area, multiple sinus formation, and a purulent discharge containing grains. ${ }^{2-4}$ The grains represent microcolonies of the causative agent. The progression of the disease is slow and painless, but may affect deep structures such as muscles, tendons, joints, fascia and bones. The skin shows a wooden fibrotic induration due to dermal sclerosis. ${ }^{3}$ Patients are otherwise in a good health condition with no satellite adenopathies. ${ }^{2,5}$

The etiologic agents of mycetoma are aerobic and anaerobic bacteria (actinomycetoma) and fungi (eumycetoma). In the tissue, these organisms are found in compact aggregates of filamentous

bacterial colonies or fungal hyphae, which will characterize the grains. These structures are the fundamental elements of the disease. The bacteria are represented by delicate filaments of about $1 \mu \mathrm{m}$ or less, which are known as actinomycotic grains, while fungi are formed by thicker and coarser filaments, measuring $2 \mu \mathrm{m}$ or more in diameter, known as eumycotic grains. ${ }^{4,5,7}$

Managing such infections is still challenging and treatment should involve early diagnosis, the use of antibiotics or systemic antifungals, and surgical removal of the lesions. ${ }^{4,8}$

In order to improve therapeutic results, healthcare professionals, especially dermatologists, must be aware of the epidemiology and clinical presentation of these infections.

\footnotetext{
Received on 01.03.2017.

Approved by the Advisory Board and accepted for publication on 19.07.2017.

* Study conducted at Hospital Regional da Asa Norte (HRAN) and Hospital Universitário de Brasília - Universidade de Brasília (HUB-UnB) - Brasília (DF), Brazil. Financial support: None.

Conflict of interests: None.

Dermatology Service. Laboratory of Medical Mycology of the University Hospital of Brasilia - University of Brasilia (HUB-UnB) - Brasilia (FD), Brazil. Dermatologic Surgery Clinic and Vitiligo Clinic of the Regional Hospital of Asa Norte (HRAN) - Brasília (FD), Brazil.
}

\section{MAILING ADDRESS:}

Eugenio Galdino de Mendonça Reis-Filho

E-mail: eugeniodermato@gmail.com 


\section{HISTORY}

The first reference to mycetoma dates from the Byzantine period (300-600 a.D.), with evidence from an adult skeleton whose morphological bone structure was suggestive of a mycetoma infection. ${ }^{6,7}$ However, the first written account of mycetoma was found in an ancient Indian religious book, Atharva Veda, where it was mentioned as "anthill foot". In 1842, Gill, a French missionary, described the first clinical cases of mycetoma in Madura, southern India, naming it "Madura foot". ${ }^{3,4,6}$ In 1860, Carter used the term 'mycetoma', being the first to describe the disease under this name. ${ }^{4,6}$ In 1913, Pinoy observed that the disease was caused by two etiologic agents and divided the disease into two categories: actinomycetoma (bacterial agents) and eumycetoma (fungal agents). ${ }^{6}$ The first attempt to map the distribution of mycetoma throughout the world was made by Abott in 1956. ${ }^{6}$ He studied 1321 cases of mycetoma in Sudan during a period of two and half years. ${ }^{3,6} \mathrm{New}$ studies were then carried out by other researchers in regions such as Congo, Somalia, Argentina and Mexico. ${ }^{3,6}$

\section{EPIDEMIOLOGY}

Although mycetoma is found worldwide, it is endemic in tropical and subtropical countries, mostly between the latitudes $15^{\circ}$ south and $30^{\circ}$ north, known as the mycetoma belt. ${ }^{1,2,6-8}$

The countries with the highest incidence of the disease are Sudan, Venezuela, Mexico, and India, but Sudan and Mexico have the highest number of cases reported. ${ }^{1,3,7,8}$ Cases have also been reported in other African countries such as Egypt, Senegal, Mauritania, Kenia, Niger, Nigeria, Ethiopia, Chad, Cameroon, Djibouti, and Somalia. ${ }^{3,46}$ In Latin America, besides Mexico which has the highest number of cases reported, the disease has also been registered in Venezuela, Colombia, Argentina, and Brazil. ${ }^{3,4}$ Other countries that have reported cases of mycetoma are the USA, Germany, the Netherlands, Turkey, Lebanon, Saudi Arabia, Iran, Philippines, Japan, Sri Lanka, and Thailand. ${ }^{3,4,6}$

The endemic areas are characterized by short rainy seasons with little daily temperature fluctuations, followed by long dry seasons with broad daily temperature fluctuations $\left(45-60^{\circ} \mathrm{C}\right.$ to $\left.15-18^{\circ} \mathrm{C}\right)$. $1,2,4,8$ Such extreme climatic conditions may contribute to the survival of the causative organism. $3,6,7$

The global incidence of actinomycetoma and eumycetoma varies from country to country and from region to region. Actinomycetoma is more prevalent in drier areas and eumycetoma in humid areas. ${ }^{2,3,6}$

Actinomycetomas (bacterial agents) are more commonly found in South and Central America, whereas eumycetomas (fungal agents) are more common in Africa. Sudan is considered the most endemic country for mycetoma in the world. In Khartroum, capital of Sudan, more than 7000 patients have been treated for mycetoma and, in $70 \%$ of cases, the causative agent has been identified as the fungus Madurella mycetomatis. ${ }^{1,6}$ In Mexico and Brasil, actinomycetomas are more prevalent and Nocardia brasiliensis is the main etiologic agent. ${ }^{1,6}$

Some of the microorganisms that cause the disease are found in the soil and can enter the human body via a thorn prick, a wood splinter or a stone cut. ${ }^{2,3,6}$
Mycetomas are considered occupational diseases of individuals who work in rural areas, such as farmers and shepherds, or that engage in activities related to the environment. $3,6,9,10$

Mycetomas can affect all age groups, but it occurs more commonly in young men aged between 20 and 40 years..$^{1,2,9}$ Men are more likely to be affected than women, with the male to female ratio ranging from $3: 1$ to $5: 1 .^{2,6}$

Environmental factors associated to genetic or immunologic predisposition can play a role in increasing the susceptibility to the disease. ${ }^{1,2,10}$

Mycetoma has no known vector or animal reservoir. ${ }^{6,9,11}$

\section{ETIOPATHOGENY}

Mycetoma can be caused by fungi (eumycetoma) or bacteria (actinomycetoma) with similar clinical features. ${ }^{4,6}$ The disease most likely initiates after a minor trauma that inoculates the causative microorganism in the subcutaneous tissue. $1,6,7,11$

Actinomycetoma can be caused by anaerobic agents (Actinomyces israelii) that are found in natural cavities of humans or other animals, mainly in the mouth or tonsils, or by aerobic agents that enter the human body via penetrating injuries. The most important agents are: Nocardia (N. brasiliensis; N. asteroides; N. otitidis-caviarum; N. transvalensis), Streptomyces somaliensis, Actinomadura (A. madurae; A. pelletieri), and new species of the genus Nocardia: N. harenae and $N$. takedensis. ${ }^{11-13}$

Approximately $50 \%$ of mycetoma are eumycetoma and the most common species are Madurella mycetomatis (70\% of cases), Madurella grisea and Scedosporium apiospermum. Other causative agents include Acremonium falciforme, A. kiliense, A. recifei, Cylindrocarpon nescens, C. destructans, Exophiala jeanselmei, Scytalidium dimidiatum, Aspergillus nidulans, Neotestudina rosatii, Leptosphaeria senegalensis, Pyrenochaeta romeroi and Phialophora verrucosa. ${ }^{13,14}$ The frequency of these species depends on the geographical region and climatic conditions. M. mycetomatis produces black grains and is typically found in tropical regions, while S. apiospermum produces white grains and is found in temperate regions. $4,9,14,15$

Once the fungus penetrates and inoculates in the subcutaneous tissue, it stays indolent until extending to deeper tissues and bones. Mycetoma can spread locally through the lymphatic system and, rarely, through the blood stream. Oral and facial mycetoma are uncommon. ${ }^{11}$

The typical clinical presentation is a painless subcutaneous mass of slow progression forming multiple sinuses that drain pus and clusters of bacterial and fungal structures called "grains". 4,9 The host's inflammatory response consists of a neutrophilic infiltrate and the formation of granulomas that typically contain grains. The clusters of fungal hyphae will vary in color according to the causative agent. ${ }^{4,9}$ Untreated infections will eventually destroy the tissues, including bones. The most frequent radiological finding in mycetoma is soft tissue swelling followed by bone sclerosis, bone cavities and periosteal reaction. ${ }^{11,16}$

After inoculation of the causative agent (fungi or bacteria) a subcutaneous infection develops. The is usually painless and processes slowly, over months and years. ${ }^{4}$ 
In malnourished patients and patients with associated illnesses (e.g. malaria, HIV/AIDS, leishmaniasis, diabetes mellitus etc.) a more intense and faster progression of the disease may occur., ${ }^{4,17}$

\section{DIAGNOSIS}

The diagnosis of mycetoma is based on clinical presentation and identification of the etiologic agents. Clinical diagnosis is characterized by a symptomatic triad: a subcutaneous mass (tumefaction), draining sinuses and grain discharge. ${ }^{1,7,17}$

The most specific diagnostic tool is the examination of the grains discharged from sinuses. Both spontaneous drainage and manually expressed material from sinus should be carefully examined macro and microscopically to visualize the grains. ${ }^{4,9}$ The samples can be obtained from any open sinus or by deep surgical biopsy (Table 1). ${ }^{4,9}$

\section{MYCOLOGIC/BACTERIOLOGIC DIAGNOSIS}

\section{Macroscopic and microscopic features of the grains}

Mycological and bacteriological examination are very important for the correct diagnosis. ${ }^{4,9,18,19}$

The grains eliminated vary in size, color and texture; on direct examination, grains are used for a fast yet temporary identification of the etiologic agents. ${ }^{4,9}$ Over 30 species have been identified as causative agents of mycetoma, but the grains of many of these agents have overlapping morphological characteristics, therefore, cultures are needed to properly identify the causative agent.

Grain size varies in diameter: in eumycetoma, such as those caused by Actinomadura madurae, Actinomadura pelletieri and by species of the genus Madurella (especially Madurella mycetomatis), grain diameter is usually $\geq 1-2 \mathrm{~mm}$; in actinomycetoma, grains are smaller and hardly visualized. Grain color of the most common species are shown in Table 1. ${ }^{5,14}$
Culture is paramount to identify the causative organisms of mycetomas. The purulent discharge sampled should be centrifuged, sedimented and washed many times with saline to eliminate contaminants. .,5,17 $^{-17}$

Colony growth should be checked daily and suspected colonies should be replicated in new media to promptly identify the etiologic agents. Eumycetoma grow slower than actinomycetoma, thus fungal cultures should be kept for up to six weeks before being discarded as negative., ${ }^{5,17,19}$

Macroscopic and microscopic features of the most common etiologic agents found in Brazil are described below:

Grains from Nocardia brasiliensis (aerobic actinomycete) measure approximately $0.1-0.2 \mathrm{~mm}$ in diameter, are irregular in shape, of soft consistency and a white-yellow color; on direct examination clubs are often not visualized. Grains are cultured in media such as Sabouraud agar, chocolate agar, and Czapeck-dox agar at room temperature and at $37^{\circ} \mathrm{C}$. After the first week, small white colonies can be observed; occasionally, colonies are covered by a thin and short white aerial mycelium related to the fragmentation of bacterial filaments. Colonies release a strong odor of "wet soil". In Gram-stained smears, $N$. brasiliensis has branched bacterial filaments that fragment into coccoid and bacillary structures; they are gram-positive and partially acid-resistant by the Kinyoun method (Figure 01). 5,14

Nocardia asteroids grows well on Sabouraud agar, chocolate agar, and Czapeck-dox agar at $25-37^{\circ} \mathrm{C}$. Initially, the colonies have an elevated, glabrous, ridged, and granular surface; color is usually orange, but can range from yellow to pink. On Gram-stained smears, branched, delicate, and twisted filaments of $1 \mu \mathrm{m}$ are observed fragmenting into bacillary and coccoid structures. ${ }^{5,14}$

On direct examination, Actinomadura madurae shows round or oval white-yellow grains that are insoluble in $\mathrm{KOH} 20 \%$ and ace-

TABLE 1: Morphological and physiological characteristics of etiologic agents

\begin{tabular}{|c|c|c|c|}
\hline Etiologic agent & Grain features & Optimal To & Essays \\
\hline Nocardia brasiliensis & $\begin{array}{l}\text { White-yellow, } 1 \mathrm{~mm} \text {, presence of clubs and } \\
\text { filamentous formations; Gram }(+) \text { and BAAR }(+)\end{array}$ & $25^{\circ} \mathrm{C}$ and $37^{\circ} \mathrm{C}$ & $\begin{array}{l}\text { Casein hydrolysis }(+) \text { Growth in } \\
\text { gelatin } 0.4 \%(+) \\
\text { Decomposes in tyrosine crystal }\end{array}$ \\
\hline Nocardia asteroides & $\begin{array}{l}\text { White-yellow, } 1 \mathrm{~mm} \text {, presence of clubs and } \\
\text { filamentous formations; Gram }(+) \text { and BAAR }(+)\end{array}$ & $25^{\circ} \mathrm{C}$ and $37^{\circ} \mathrm{C}$ & $\begin{array}{l}\text { Does not hydrolyze casein }(-) \text {, does } \\
\text { not grow in gelatin } 0.4 \%(-) \text {, does not } \\
\text { decompose tyrosine }(-)\end{array}$ \\
\hline Actinomadura madurae & White-yellow, round or oval & $37^{\circ} \mathrm{C}$ & Gelatin (-) \\
\hline Acremonium kiliense & $\begin{array}{l}\text { White-yellow, } 20 \mathrm{~mm} \text {, irregular shape, with } \\
\text { fragmented hyphae }\end{array}$ & $26^{\circ} \mathrm{C}$ to $30^{\circ} \mathrm{C}$ & $\begin{array}{l}\text { Assimilates glicose, maltose, } \\
\text { peptone }(+)\end{array}$ \\
\hline Scedosporium apiospermum & $\begin{array}{l}\text { Hyaline white, } 2.0 \text { to } 4.0 \mathrm{~mm} \text {, multiple shapes, soft, } \\
\text { with septate hyphae and chlamydospores }\end{array}$ & $37^{\circ} \mathrm{C}$ & $\begin{array}{l}\text { Starch hydrolysis, proteolytic } \\
\text { activity in gelatin medium }\end{array}$ \\
\hline Madurella grisea & $\begin{array}{l}\text { Black, } 1 \text { to } 2 \mathrm{~mm} \text {, oval or irregular shape, large } \\
\text { hyphae and chlamydospores }\end{array}$ & 26 to $30^{\circ} \mathrm{C}$ & $\begin{array}{l}\text { Assimilates glicose, maltose, } \\
\text { saccharose, galactose, urea }(+), \\
\text { peptone }(+) \text { and asparagine }\end{array}$ \\
\hline Madurella mycetomatis & Black, large, $5 \mathrm{~mm}$ or more, interlacing & $37^{\circ} \mathrm{C}$ & $\begin{array}{l}\text { Assimilates lactose, glicose, maltose, } \\
\text { galactose, urea, peptone, asparagine } \\
\text { and saccharose (-) }\end{array}$ \\
\hline
\end{tabular}


tic acid. It grows at room temperature, with best development at $37^{\circ} \mathrm{C}$. Cultures are grown in vegetable broth, glycerol-gelatin and Lowenstein-Jensen media; colonies are protruding, round, and white-yellow that later become pink or red-raw. ${ }^{5,14}$

Madurella grisea has black, oval or irregularly shaped grains that measure $\geq 1-2 \mathrm{~mm}$; growth is slow and may reach $17-25 \mathrm{~mm}$ in diameter in 30 days at temperatures ranging between $26-30^{\circ} \mathrm{C}$. Colonies are ridged and cerebriform with irregular and hardened edges; it has a grey to olive-green color that later becomes blackened with a velvety surface. The microculture of colonies shows septate and sterile mycelia measuring $1-3 \mu \mathrm{m}$ in diameter with rare chlamydospores and large moniliform hyphae $(3-5 \mu \mathrm{m})$. It grows well in Sabouraud agar and potato agar. ${ }^{5,14}$

Madurella mycetomatis has black, big grains of $5 \mathrm{~mm}$ or more (Figure 2). Initially, colonies are yellow or brown with a ridged surface and are frequently covered by a short aerial gray mycelium. Colonies grow well on potato agar, cornmeal agar, Sabouraud agar, and Czapeck-dox agar at $37^{\circ} \mathrm{C}$. Colonies have moniliform dematiaceous hyphae and chlamydospores of $25 \mu \mathrm{m}$; after two months, black sclerotia measuring $1 \mu \mathrm{m}$ in diameter formed by polygonal mycelia are observed. It has two types of sporulation: simple and branched conidiophore and innumerous chlamydospores. Madurella mycetomatis was found to assimilate lactose but not saccharose. ${ }^{5,14}$

Acremonium kiliense has white-yellow irregularly shaped grains with $20 \mathrm{~mm}$ and fragmented hyphae. Colony growth is fast in Czapeck-dox agar, potato agar and cornmeal agar at temperatures of $26-30^{\circ} \mathrm{C}$; colonies have a velvety aspect and a white-grey color. The conidiophores have a smooth wall, with hyaline, unicellular and straight conidia in the apical portion, kept together by a mucilaginous substance..$^{5,14}$

On direct examination, Scedosporium apiospermum has hyaline white grains measuring 2-4 mm in diameter that vary in shape. Grains are soft and have septate hyphae and chlamydospores. Their colonies grow well at room temperature and at $37^{\circ} \mathrm{C}$ in cornmeal agar, potato agar, Sabouraud agar, and Czapeck-dox agar. Colonies are dark-gray, have isolated annelloconidia formed at the apex of the annellophores and pyriform aleuriospores that are distributed in the apices of simple or branched conidiophores. S. apiospermum is the anamorph (or asexual) form of the species Pseudallescheria boydii (Figure 3). ${ }^{5,14}$

Tables 1 and 2 show the morphologic and laboratory features of the etiologic agents more frequently isolated in mycetomas. ${ }^{14}$

\section{HISTOPATHOLOGICAL DIAGNOSIS}

Grains can be visualized with hematoxylin \& eosin staining (H\&E) and by special staining techniques, such as the Periodic-acid-Schiff (PAS) and Grocott-Gomori silver staining. Actinomycetoma should also be investigated using Gram staining. ${ }^{4,5}$

Histopathology shows granulomas of epithelioid cells and multiple giant cells. In the eumycetoma, the grains are characterized by clusters of branched hyphae radially arranged that occasionally forms vacuoles. Pink, sharp, large hyphae can be seen, surrounded
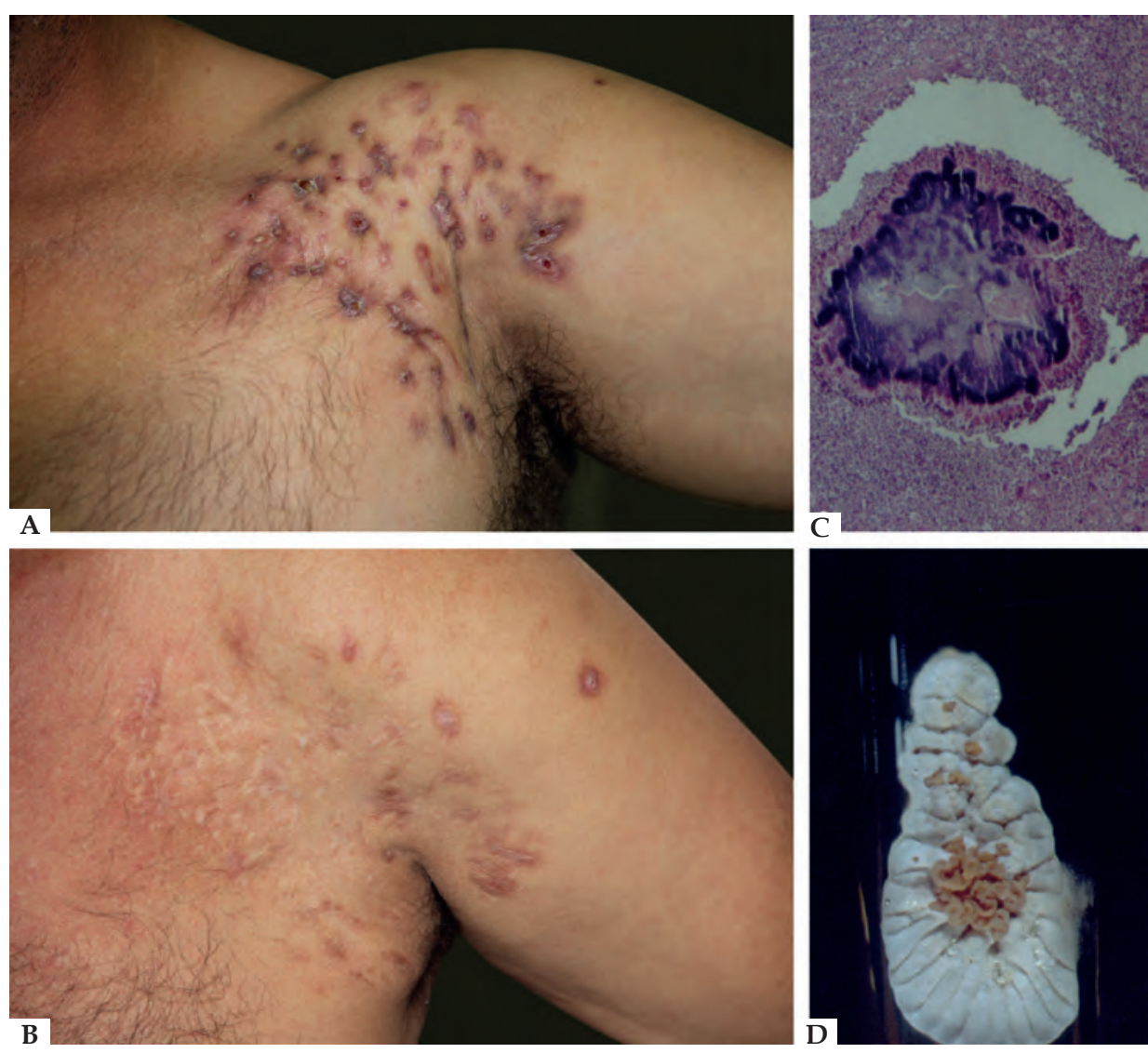

Figure 1: A) Actinomycetoma -

Nocardia brasiliensis.

B) After clinical and surgical treatment.

C) Actinomycetoma grain on histopathology (Hematoxylin \& eosin, X40). D) Typical colony of Nocardia brasiliensis 
by a basophilic component (H\&E stain). The grains show round, sometimes oval or kidney-like configurations. ${ }^{4,5,7}$

In actionmycetoma, the delicate filaments are involved by an antigen-antibody complex forming an eosinophilic fringe (clubs), similar to the Splendore-Hoeppli phenomenon, that are found around the grains. ${ }^{4,5,7}$

Histopathology is useful to confirm the clinical diagnosis and distinguish eumycetoma from actinomycetoma, but it does not identify the causative agent. ${ }^{3,7}$ Histological sections reveal a granuloma containing grains located in microabscesses. ${ }^{5,7}$

\section{MOLECULAR DIAGNOSIS}

Recently, Molecular Biology techniques have become increasingly important in the identification of genera and species. ${ }^{5}$ However, due to the lack of standardized techniques and the high cost, molecular diagnosis should be considered a complementary diagnostic tool and not a replacement for the conventional methods. ${ }^{1,14}$

\section{RADIOLOGICALIMAGING DIAGNOSIS}

Several imaging techniques can be used to determine the extent of lesions, including conventional X-rays, ultrasonography, magnetic resonance and computed tomography. ${ }^{5,7,15}$ These radiological images are essential for surgical planning. ${ }^{20}$
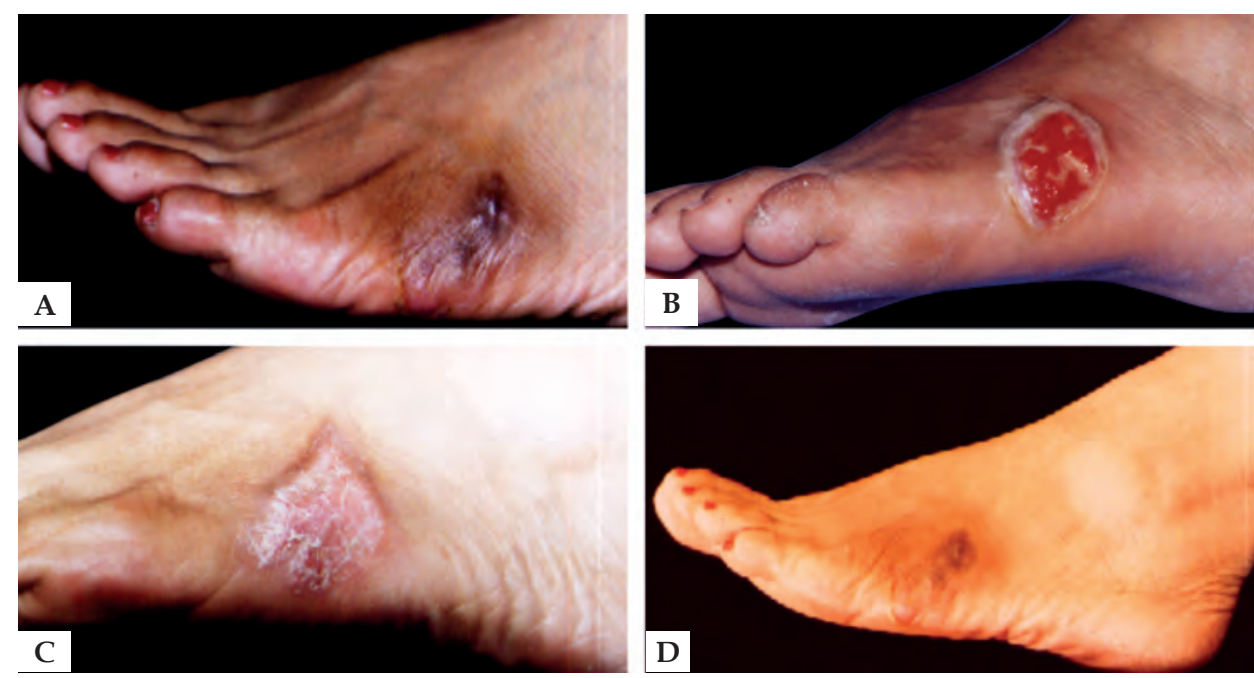
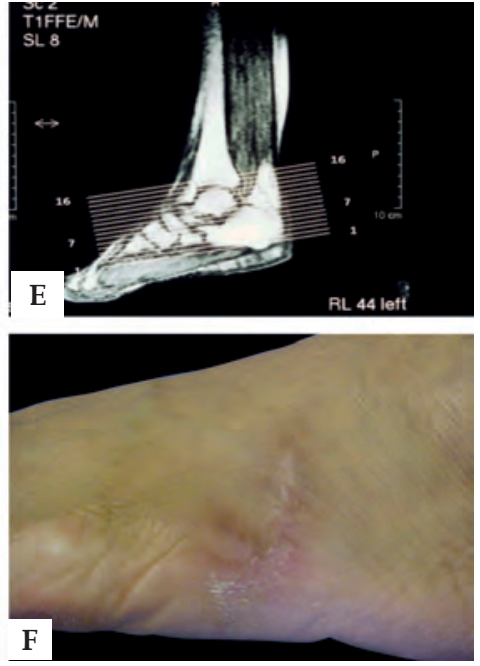

Figure 2: A) Eumycetoma - Madurella mycetomatis. B) After deep surgical debridement. C) 30 days after surgical procedure. D) Six months after surgical procedure. E) Magnetic resonance imaging (MRI) of the tumor. F) Patient after mycological and clinical cure
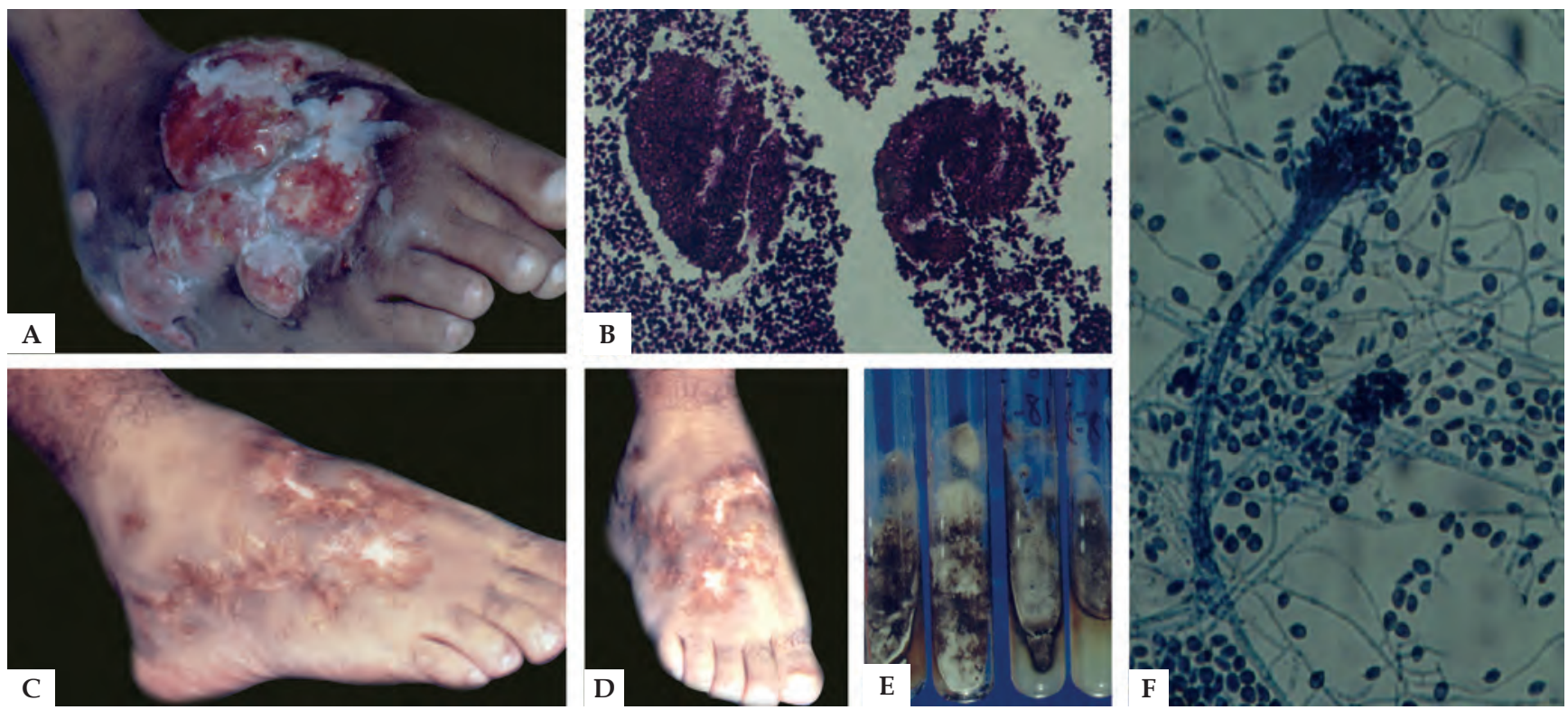

Figure 3: A) Eumycetoma - Scedosporium apiospermum. B) Eumycetoma grain on histopathology (Hematoxylin \& eosin, X40). C and D) After clinical and surgical treatment. E) Cultures in specific media. F) Strands of hyphae and conidia - Synnema (Lactophenol cotton blue X20) 
TABLE 2: Etiologic agents, macroscopic and microscopic features and culture media for the colonies

\begin{tabular}{|c|c|c|c|}
\hline Etiologic agent & Macroscopic characteristics of colonies & Culture medium & Microscopic characteristics of colonies \\
\hline Nocardia brasiliensis & $\begin{array}{l}\text { White, wrinkled on the surface, yellow or } \\
\text { orange underneath. Odor of "wet soil". }\end{array}$ & $\begin{array}{l}\text { Chocolate agar } \\
\text { Sabouraud agar } \\
\text { Czapeck-dox agar }\end{array}$ & $\begin{array}{l}\text { Fine filaments, } 1 \mu \mathrm{m} \text {, that fragments } \\
\text { into bacillary structures }\end{array}$ \\
\hline Nocardia asteroides & $\begin{array}{l}\text { White, wrinkled on the surface, yellow or } \\
\text { orange underneath. Odor of "wet soil". }\end{array}$ & $\begin{array}{l}\text { Chocolate agar } \\
\text { Sabouraud agar } \\
\text { Czapeck-dox agar }\end{array}$ & $\begin{array}{l}\text { Fine filaments, } 1 \mu \mathrm{m} \text {, that fragments } \\
\text { into bacillary structures }\end{array}$ \\
\hline Actinomadura madurae & $\begin{array}{l}\text { Glabrous, serous, ridged colony with grey } \\
\text { folds and flat border }\end{array}$ & $\begin{array}{l}\text { Vegetable broth } \\
\text { Glycerol-gelatin } \\
\text { Lowenstein-Jensen }\end{array}$ & $\begin{array}{l}\text { Branched, long and twisted filaments, } \\
\text { smaller than } 1 \mu \mathrm{m} \text { in diameter. Gram + }\end{array}$ \\
\hline Acremonium kiliense & $\begin{array}{l}\text { Slow growth, short, white-grey to pink aerial } \\
\text { mycelium, violet reverse }\end{array}$ & $\begin{array}{l}\text { Sabouraud agar } \\
\text { Czapeck-dox agar } \\
\text { Potato agar } \\
\text { Cornmeal agar }\end{array}$ & $\begin{array}{l}\text { Hyaline hyphae, simple conidiophore } \\
\text { and apical conidia clustered into a } \\
\text { circle kept together by mucilaginous } \\
\text { substances }\end{array}$ \\
\hline Scedosporium apiospermum & $\begin{array}{l}\text { Fast filamentous growth, cottony dark-grey } \\
\text { mycelium }\end{array}$ & $\begin{array}{l}\text { Sabouraud agar } \\
\text { Chocolate agar } \\
\text { Czapeck-dox agar }\end{array}$ & $\begin{array}{l}\text { Isolated annelloconidia formed at } \\
\text { the apex of annellospores. Pyriform } \\
\text { aleuriospores distributed in the apices } \\
\text { of simple or branched conidiospores. } \\
\text { Strands of conidiospores form coremia. }\end{array}$ \\
\hline Madurella grisea & $\begin{array}{l}\text { Grey to olive-green, circular with irregular } \\
\text { edges, ridged surfaces and dark reverse }\end{array}$ & $\begin{array}{l}\text { Sabouraud agar } \\
\text { Potato agar }\end{array}$ & $\begin{array}{l}\text { Dematiaceous septate mycelia with } \\
\text { rare chlamydiospores; presence of } \\
\text { sclerotia }(\mathrm{AB})\end{array}$ \\
\hline Madurella mycetomatis & Yellow or brown, ridged surfaces & $\begin{array}{l}\text { Sabouraud agar } \\
\text { Potato agar } \\
\text { Cornmeal agar } \\
\text { Czapeck-dox agar }\end{array}$ & $\begin{array}{l}\text { Moniliform, dematiaceous hyphae and } \\
\text { chlamydospores, } 25 \mu \mathrm{m} \text { in diameter; } \\
\text { simple and branching conidiophores; } \\
\text { multiple chlamydospores }\end{array}$ \\
\hline
\end{tabular}

Over the last years, magnetic resonance imaging (MRI) has been considered as a diagnostic and planning tool for the treatment and prognosis of the disease..$^{5,15,20}$ The changes observed will guide the surgeon in the removal of the affected tissue and during follow-up. The images should be reviewed every 6 months. ${ }^{15,20}$

\section{TREATMENT}

Treatment of mycetoma depends on a correct diagnosis. It is important to define the fungal or bacterial etiology because the treatments are different. ${ }^{1,4,5,8}$. Actinomycetoma is treated with antibiotics, which can be used isolated or in different combinations, depending on the severity, extension and location of the lesions. ${ }^{4,8}$ However, we believe antibiotics combined with surgical procedures have the best therapeutic response. Eumycetoma is treated with systemic antifungals and surgical excision. ${ }^{4,8,16}$ Eumycetomas may affect deeper tissues, leading to wide surgical excisions and sometimes amputations. ${ }^{17}$ In our routine, stepwise surgical procedures are carried out every 150-180 days to remove the infected tissue while maintaining the clinical treatment. This has avoided limb amputations in our patients (42 cases). Patient follow-up is continuous: every four months during the first two years, until complete clinical and radiological cure is reached; every six months to control for relapsing lesions through laboratory and radiological investigations.
Effective treatment of actinomycetoma began in the 1940s and 1950s with sulphonamides and diaminodiphenyl sulfone (Dapsone - DDS), achieving cure in some cases. In the 1960s, trimethoprim/sulfamethoxazole (TMP-SMX) became the standard treatment for actinomycetoma. However, in patients resistant to TMP-SMX, other antibiotics were used, such as streptomycin, isoniazid, rifampicin and minocycline. . $^{8,22}$

Currently, the first-line treatment for actinomycetoma is amikacin $(15 \mathrm{mg} / \mathrm{kg} /$ day) during three weeks combined with TMPSMX $(40 / 8 \mathrm{mg} / \mathrm{kg} /$ day) every 12 hours during five weeks. One to four 5 -week cycles are recommended. Renal and audiometric monitoring is compulsory before, in between and after the cycles. ${ }^{8}$

In refractory cases or those with allergies to the combination, TMP-SMX should be replaced by amoxicillin-clavulanate and amikacin should be replaced by netilmicin. During pregnancy, monotherapy with amoxicillin-clavulanate is indicated. In cases resistant to TMP-SMX, amikacin is associated to a carbapenemic, such as imipenem or meropenem. ${ }^{8}$

In 26 years treating mycetoma patients, we have observed recurrences and refractory responses to monotherapies and to the combinations described above. For the last five years, we have chosen to treat actinomycetomas with a combination of antibiot- 
ics and surgical procedures. Currently, TMP-SMX $(8 / 40 \mathrm{mg} / \mathrm{kg} /$ day every $12 \mathrm{~h}$ ) is prescribed continuously, combined with 3-week cycles of amikacin $(15 \mathrm{mg} / \mathrm{kg} /$ day) and imipenem (1500mg IV). Six to eight cycles are recommended with a 60 to 90-day interval between cycles; TMP-SMX is maintained until the end of the last cycle. Imipenem can be replaced by meropenem with similar results and TMP-SMX can be replaced by doxycycline (100mg every $12 \mathrm{~h}$ ) or amoxicillin-clavulanate. Kidney, liver and auditory functions should be monitored before, during and after treatment cycles. Radiological controls with MRI are done every six months. ${ }^{17}$

It is important to perform sensitivity tests to antibiotics to confirm strand sensitivity, thus optimizing their use. ${ }^{18}$

Eumycetoma is a neglected disease with few studies targeting its treatment, thus prospective clinical studies are needed to evaluate the therapeutic potential of the existing antifungals. ${ }^{8,17,22}$

Itraconazole is the most commonly used drug for the treatment of eumycetoma. Its bioavailability is variable and absorption is related to stomach acidity and food intake. Existing reports indicate a favorable clinical response to its prolonged use, especially if followed by surgical excision. ${ }^{4,8}$

We believe the best treatment is itraconazole $200 \mathrm{mg} / \mathrm{VO}$ every $12 \mathrm{~h}$ for two years combined with surgical procedures every 150 180 days. Maintenance should be done with $200 \mathrm{mg} /$ day for $8-10$ years, with laboratory and radiological controls.

For almost three decades, amphotericin B was the only systemic antifungal available. It was not widely used for eumycetoma due to its toxicity and the need to be administered parenterally for prolonged periods. There is a report of its use in a case series in $\mathrm{Su}-$ dan with disappointing results.
Ketoconazole has a limited therapeutic response in eumycetomas, with doses ranging between $200-400 \mathrm{mg}$ / day for 8 to 24 months of continuous use. Ketoconazole it is not recommended as first-line treatment and its use for prolonged periods should be avoided due to its side effects, such as liver and adrenal toxicity. ${ }^{4,8}$

Fluconazole has also been reported as ineffective in the treatment of eumycetomas. ${ }^{4,8}$

New drugs belonging to the azole class have a broad spectrum, good bioavailability and low toxicity. In mycetoma, they are effective for the prolonged treatment of outpatients. However, there are limited studies in vitro and in vivo. Voriconazole and posaconazole were assessed in a small number of patients with promising results. Nonetheless, despite the good in vitro activity, prolonged treatment seems to be needed. Isavuconazole and fosravuconazole had excellent results in vitro, but no reports in vivo. Prospective studies are needed necessary to evaluate these antifungals. ${ }^{4,8}$

High-dose terbinafine $(1000 \mathrm{mg} /$ day) for periods ranging from 24-48 weeks was effective against eumycetomas caused by Exophiala jeanselmei: $55 \%$ of patients showed a significant improvement while $25 \%$ were cured. However, terbinafine was not effective in deep infections due to S. apiospermum. ${ }^{4,8}$

There are no clinical data about the efficacy of echinocandins in eumycetomas. ${ }^{4,8}$

\section{SURGICAL TREATMENT}

Surgical treatment is indicated both for small local lesions, and for massive compact lesions in order to reduce the mycetoma load and provide a better response to clinical therapy., ${ }^{9,19,22}$ Antimicrobials should be used 3-6 months prior to surgery in order to form a fibrous capsule around the lesions, making surgical dissection and excision easier. ${ }^{1,4}$
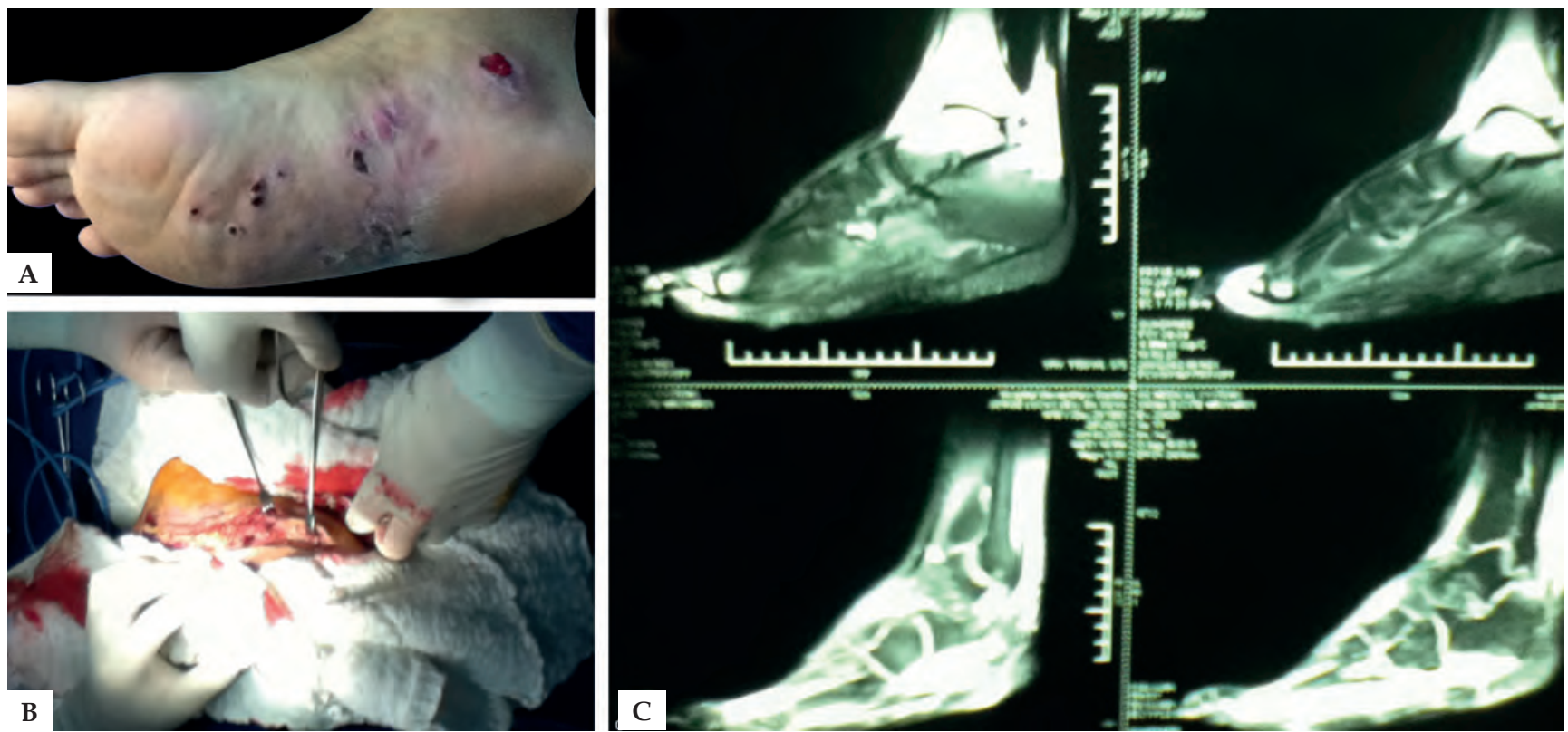

Figure 4: A) Clinical aspect of the symptomatic triad: tumefaction, sinuses and grains. B) Surgical procedure demonstrating debridement. C) MRI of the foot 
Surgical intervention for mycetoma can cause morbidity, deformities and disabilities, particularly in the advanced stages of the disease. ${ }^{8,17,20,23}$

In general, bacterial mycetoma is likely to have good response rates to clinical treatment, in contrast to fungal mycetoma, that requires prolonged medical treatment and surgery. ${ }^{8,20}$

Radiological examination is important for surgical planning. Ultrasound guided surgery can be useful to determine the precise location, size and the extension of the lesion. ${ }^{17}$

Careful surgical dissection, with safety margins, is necessary for an appropriate excision of the infected tissue, avoiding recurrence of the disease (Figure 4). ${ }^{17,20,23}$

Indications for surgery: the ground rule in our service is to treat all mycetoma surgically. Small, well defined lesions require fewer surgical interventions; however, in individuals that are not responding well to the clinical treatment, a greater number of surgical procedures is needed in order to reduce the dense, compact fungal load found in the lesions. Surgery can be a life-saving procedure in late stages of the disease, which can involve secondary bacterial infection, sepsis, and massive bone involvement. ${ }^{1,8,20}$ Commonly, bones are studded with multiple cemented cavities containing grains and fibrous tissue. The debridement of the bone must be done carefully, removing grains and fibrous tissue from the cavities. ${ }^{8,20}$

In mycetoma, the infection usually spreads along the tissue levels forming deep pockets that are not easily detected. These pockets should be identified precisely to reduce post-operative recurrence. All damaged tissue must be debrided..$^{8,20}$
After debridement, the surgical field should be thoroughly irrigated with saline to remove any grains that are left or infected tissue. Finally, the surgical field should be rinsed and irrigated methodically with iodine solution and hydrogen peroxide multiple times to remove and destroy hyphae and grains that have been left behind. ${ }^{20}$

In large lesions, the wounds are left to secondary intention healing, with the formation of fibrous tissue, or are closed with a skin graft in a later stage, after the development of a good granulation tissue. ${ }^{20}$

Early movement and physical therapy are compulsory for better surgical results, avoiding joint rigidity and reducing deformities and disabilities. ${ }^{8,20}$

The use of hydrogen peroxide on post-operative wounds is recommended..$^{20}$

\section{CONCLUSIONS}

In view of the prolonged treatment and devastating consequences of mycetomas, with the need for aggressive treatment and mutilating surgeries, more attention from the professionals that treat the disease should be given, considering all aspects that focus on a better quality of life for those affected. Knowledge gaps must be bridged and awareness on mycetoma must reach health professionals who work in primary care, so they can diagnose and refer patients to specialists early. Guidance and preventive measures promoting the use of adequate shoes and clothing should be offered to those who work in ruralareas. 


\section{REFERENCES}

1. Zijlstra EE, van de Sande WWJ, Welsh 0, Mahgoub ES, Goodfellow M, Fahal AH Mycetoma: a unique neglected tropical disease. Lancet Infect Dis. 2016;16:100112.

2. Bonifaz A, Tirado-Sánchez A, Calderón L, Saúl A, Araiza J, Hernández M, González GM, Ponce RM. Mycetoma: Experience of 482 Cases in a Single Center in Mexico. PLoS Negl Trop Dis. 2014;8:e3102.

3. Van de Sande WW. Global Burden of Human Mycetoma: A Systematic Review and Meta-analysis. PLoS Negl Trop Dis. 2013;7:e2550.

4. Nenoff P, van de Sande WW, Fahal AH, Reinel D, Schöfer H. Eumycetoma and actinomycetoma - an update on causative agents, epidemiology, pathogenesis, diagnostics and therapy. J Eur Acad Dermatol Venereol. 2015;29:1873-83.

5. van de Sande WW, Fahal AH, Goodfellow M, Mahgoub el S, Welsh 0, Zijlstra EE. Merits and Pitfalls of Currently Used Diagnostic Tools in Mycetoma. PLoS Neg Trop Dis. 2014;8:e2918.

6. Lichon V, Khachemoune A. Mycetoma : a review. Am J Clin Dermatol 2006;7:315-21.

7. Venkatswami S, Sankarasubramanian A, Subramanyam S. The Madura Foot: Looking Deep. Int J Low Extrem Wounds. 2012;11:31-42.

8. Welsh 0, Al-Abdely HM, Salinas-Carmona MC, Fahal AH. Mycetoma Medica Therapy. PLoS Negl Trop Dis. 2014;8:e3218.

9. Mattioni S, Develoux M, Brun S, Martin A, Jaureguy F, Naggara N, Bouchaud 0 . Management of mycetomas in France. Med Mal Infect. 2013;43:286-94.

10. Tomczyk S, Deribe K, Brooker SJ, Clark H, Rafique K, Knopp S, Utzinger J, et al . Association between Footwear Use and Neglected Tropical Diseases: A Systematic Review and Meta-Analysis. PLoS Negl Trop Dis. 2014;8:e3285.

11. Fahal AH. Mycetoma: a thorn in the flesh. Trans R Soc Trop Med Hyg. 2004;98:3-11.

12. Gooptu S, Ali I, Singh G, Mishra RN. Mycetoma foot. J Family Community Med. J Family Community Med. 2013;20:136-8.

13. Buonfrate D, Gobbi F, Angheben A, Marocco S, Farina C, Van Den Ende J, et al Autochthonous cases of mycetoma in Europe: report of two cases and review of literature. PLoS One. 2014;9:e100590

14. Lacaz CS, Porto E, Martins JEC, Heins-Vaccari EM, Takahashi de Melo N. Tratado de Micologia Médica. Sarvier: São Paulo; 2002.

15. Omer RF, Seif El Din N, Abdel Rahim FA, Fahal AH. Hand Mycetoma: The Mycetoma Research Centre Experience and Literature Review. PLoS Negl Trop Dis. 2016:10:e0004886.
16. White EA, Patel DB, Forrester DM, Gottsegen CJ, O'Rourke E, Holtom P, et al Madura foot: two case reports, review of the literature, and new developments with clinical correlation. Skeletal Radiol. 2014;43:547-53.

17. Zein HA, Fahal AH, Mahgoub el S, El Hassan TA, Abdel-Rahman ME. Predictors of cure, amputation and follow-up dropout among patients with mycetoma seen at the Mycetoma Research Centre, University of Khartoum, Sudan. Trans R Soc Trop Med Hyg. 2012;106:639-44.

18. Yousif BM, Fahal AH, Shakir MY. A new technique for the diagnosis of mycetoma using fixed blocks of aspirated material. Trans R Soc Trop Med Hyg. 2010:104:6-9.

19. López-Martínez R, Méndez-Tovar LJ, Bonifaz A, Arenas R, Mayorga J, Welsh O, et al. Update on the epidemiology of mycetoma in Mexico. A review of 3933 cases. Gac Med Mex. 2013;149:586-92.

20. Suleiman SH, Wadaella el S, Fahal AH. The Surgical Treatment of Mycetoma. PLoS Negl Trop Dis. 2016;10:e0004690.

21. Buonfrate D, Gobbi F, Angheben A, Marocco S, Farina C, Van Den Ende J, et al. Autochthonous cases of mycetoma in Europe: report of two cases and review of literature. PLoS One. 2014;9:e100590

22. Mencarini J, Antonelli A, Scoccianti G, Bartolini L, Roselli G, Capanna R, et al. Madura foot in Europe: diagnosis of an autochthonous case by molecular approach and review of the literature. New Microbiol. 2016;39:156-9.

23. Brufman T, Ben-Ami R, Mizrahi M, Bash E, Paran Y. Mycetoma of the Foot caused by madurella mycetomatis in immigrants from sudan. Isr Med Assoc J. 2015;17:418-20.

How to cite this article: Reis CMS, Reis-Filho EGM. Mycetomas: an epidemiological, etiological, clinical, laboratory and therapeutic review. An Bras Dermatol. 2018;93(1):8-18. 


\section{QUESTIONS}

1. Which of the following microorganisms causes eumycetoma:
a) Cladosporium carrionii.
b) Sporothrix schenckii.
c) Scedosporium apiospermum.
d) Streptomyces somaliensis.

2. Red grains are seen in a cutaneous lesion. Macroscopically, the grounded grains have fine delicate filaments with $1 \mu \mathrm{m}$ width that branch off from a necrotic center. The most likely diagnosis for this case is:
a) Chromoblastomycosis.
b) Eumycetoma.
c) Actinomycetoma.
d) Sporotrichosis.

3. The etiologic agent e most commonly found in Brazil is:
a) Madurella grisea.
b) Nocardia brasiliensis.
c) Phialophora verrucosa.
d) Madurella mycetomatis.

4. Which of the following organism is weakly acid-fast:
a) Nocardia brasiliensis.
b) Madurella mycetomatis.
c) Streptomyces griseus.
d) Phialophora verrucosa.

\section{Which of the following statements is correct:}

a) Grains are observed in mycetoma caused by Nocardia, but in nocardiosis usually there are no grains.

b) The typicall sulphur colored grains are present in actinomycosis and mycetoma caused by the same organisms.

c) Acremonium kiliensis is an etiologic agent of actinomycetoma.

d) Only actinomycete fungi and bacteria can produce grains in the tissue.

6. Which of the morphological features are not compatible to its respective etiologic agent:

a) Nocardia brasiliensis has an odor of "wet soil".

b) Scedosporium apiospermum has multiple pyriform aleuriospores distributed in the apices of simple conidiophores.

c) Acremonium kiliense exhibit simple conidiophore with a single conidium on the extremity of the conidiophore.

d) Madurella mycetomatis has simple conidiophores in a rosette formation.

7. Mycetomas occur more commonly in which age group:
a) 0 - 20 years.
b) 20 - 40 years.
c) 40 - 60 years.
d) over 60 years.

8. The disease that is not a differential diagnosis of mycetoma is:
a) Paracoccidioidomycosis.
b) Tegumentary leishmaniasis.
c) Entomophthoromycosis.
d) Tuberculosis.

9. Regarding the etiopathogenesis of mycetoma, which of the following statements is correct:

a) Mycetoma can spread locally through the lymphatic system and blood stream.

b) The symptomatic triad consists of a painless subcutaneous mass that progresses rapidly, forming sinuses that drain pus and grains.

c) The disease progresses similarly in immunocompetent and immunosuppressed patients.

d) The clinical presentation of actinomycetomas and eumycetomas are similar, however, their frequency depends on geographic location and climatic factors.

10. A 50-year-old patient from a rural area presents with swelling of the lower limb, sinuses, pus and grains. He is attended at the Dermatology Outpatient clinic. The best initial approach would be:

a) Deep biopsy with samples to histopathology, bacteriology, mycology and request imaging studies.

b) Send samples for Molecular Biology studies followed by immediate surgical treatment with radiological follow-up.

c) Start treatment with sulfamethoxazole-trimethoprim, regardless of the etiologic agent and wait for culture results to define a targeted treatment.

d) Refer the patient to the surgeon for limb amputation and subsequent clinical treatment to control hematogenous spread.

11. The best treatment combination for a patient with eumycetoma caused by Madurella mycetomatis would be:

a) Fluconazole $300 \mathrm{mg}$, po, every 12 hours for 2 years, combined with surgical procedure every 6 months.

b) IV Amphotericin B, $2-5 \mathrm{mg} / \mathrm{kg} /$ day, total of $3 \mathrm{~g}$, and maintenance with sulfamethoxazole-trimethoprim for 5 years.

c) Voriconazole 200mg, po, every 12 hours for 2 months has the best cost-benefit: satisfactory results and shorter treatment period.

d) Itraconazole $200 \mathrm{mg}$, every 12 hours for a prolonged period, combined with deep surgical debridement every 6 months with laboratory and radiological follow-up.

12. The best therapeutic approach for a patient diagnosed with actinomycetoma caused by Nocardia braziliensis would be:

a) Monotherapy with sulfamethoxazole-trimethoprim $40 / 8 \mathrm{mg} /$ $\mathrm{kg}$ / day for 3 weeks; 1-4 cycles.

b) Amoxicillin-clavulanate $500 / 125 \mathrm{mg} /$ day, every 8 hours for 3-6 months.

c) First-line treatment consisting of amikacin $15 \mathrm{mg} / \mathrm{kg} /$ day com- 
bined to an IV carbapenemic 500mg every 8 hours for 3-6 months. d) Amikacin $15 \mathrm{mg} / \mathrm{kg} /$ day for 3 weeks combined with sulfamethoxazole-trimethoprim $40 / 8 \mathrm{mg} / \mathrm{kg} /$ day for 5 weeks; $1-4$ cycles.

13. Which of the statements regarding the surgical approach of mycetoma is correct:

a) It is the most efficient treatment and should be the first approach in actinomycetoma and eumycetoma.

b) Surgical dissection and resection should be performed after the use of an antimicrobial, allowing a fibrous capsule to form around the lesions.

c) Radiological tests are not important for surgical planning since mycetoma is not invasive and its limits are easily identified.

d) Neurological and orthopedic complications are inevitable since nerves and tendons are affected by the disease and need to be removed.

14. Regarding the epidemiological characteristics of mycetoma, it is correct to state that:

a) Men and women are equally affected since the disease affects young rural workers.

b) The disease is transmitted from person to person; it is common for family members living in the same area to present a similar clinical picture.

c) Mycetoma has a known reservoir. Etiologic agents are found in the soil. Rural workers in contact with wild animals are most susceptible to the disease.

d) The causative microorganisms are found in the soil; the infection starts with the inoculation through injuries on the skin.

15. Regarding the clinical features of mycetoma, it is correct to state that:

a) The evolution of the disease is painful and patient's overall health condition is compromised. Satellite adenopathies are observed.

b) The affected areas are indurated due to dermal sclerosis, compromising deep structures such as tendons and bones.

c) The purulent discharge containing grains eliminated from sinuses are the main elements for the diagnosis of mycetoma since pure colonies are always obtained from cultures.

d) Mycetoma is an acute skin infection characterized by a symptomatic triad (tumefaction, multiple sinus formation and grains) that usually affects the trunk.

16. Regarding grains, which are the main diagnostic elements of mycetoma, it is correct to state that:

a) They are only visible under a microscope.

b) Grains from actinomycetoma and eumycetoma have similar morphologic features on histopathology.

c) Grains are eliminated from sinuses, have variable size, color and texture and, although cultures are needed to accurately identify the causative agent, they can be used for a temporary identification.

d) The eosinophilic fringe resembling the Splendore-Hoeppli phenomenon is pathognomic in mycetoma.
17. Regarding the occurrence of mycetoma, it is correct to state that:

a) Mycetoma is found in few regions of the world; although it is endemic in tropical and subtropical countries, it is currently only found in African countries.

b) In the American continent, actinomycetomas are rare.

c) Actinomycetomas are prevalent in drier areas, as opposed to eumycetomas, which are more commonly found in rainy areas.

d) There are no cases reported in Europe; in the Americas, cases have only been reported in developing countries such as Mexico and Brazil.

18. Which of the following statements is incorrect:

a) Iodine solutions and hydrogen peroxide are not recommended for the irrigation of affected tissues or for post-surgical dressings.

b) Early diagnosis of mycetoma is key; late diagnosis may lead to mutilating treatments.

c) Health care professionals that work with primary care in rural areas must engage in preventive measures, such as advising rural workers to use adequate shoes and clothes.

d) Early movement and physical therapy are compulsory after surgery.

19. Actinomycetoma is caused by anaerobic and aerobic bactéria. Which of the following microorganims does not cause actinomycetoma:

a) Actinomadura madurae.

b) Streptomyces somaliensis.

c) Nocardia brasiliensis.

d) Leptosphaeria senegalensis.

20. The most commonly used culture media for isolation of mycetoma are:

a) Sabouraud agar, chocolate agar, BHI agar.

b) rice agar, Sabouraud agar, potato agar.

c) BHI agar, Mycosel agar, Sabouraud agar, blood agar.

d) blood agar, BHI agar, Czapeck-dox agar.

\begin{tabular}{|c|c|c|c|}
\hline \multicolumn{4}{|c|}{ Answer key } \\
\hline \multicolumn{4}{|c|}{$\begin{array}{l}\text { Leprosy: current situation, clinical and laboratory as- } \\
\text { pects, treatment and perspective Uniform Multidrug Ther- } \\
\text { apy for all leprosy patients. An Bras Dermatol. 2017;92(6): } \\
761-73 \text {. }\end{array}$} \\
\hline 1. D & 6. $C$ & 11. B & 16. D \\
\hline 2. B & 7. $C$ & 12. $\mathrm{C}$ & 17. D \\
\hline 3. B & 8. D & 13. C & 18. B \\
\hline 4. A & 9. A & 14. D & 19. B \\
\hline 5. B & 10. D & 15. D & 20. D \\
\hline
\end{tabular}

Papers

Information for all members: The EMC-D questionnaire

is now available at the homepage of the Brazilian Annals of

Dermatology: www.anaisdedermatologia.org.br. The dead-

line for completing the questionnaire is 30 days from the date

of online publication. 